ISSN: 2277-3754

ISO 9001:2008 Certified

International Journal of Engineering and Innovative Technology (IJEIT)

Volume 11, Issue 7, January 2022

\title{
Analysis of low force friction welding process in the industrial environment
}

\author{
Pawel Zurawski \\ Stalowa Wola 37-450, Poland
}

\begin{abstract}
The low force friction welding process is a relatively new technology for welding two components together. The process developed just a few years ago has not been sufficiently researched to date to extend the knowledge about the process and its advantages. Under this process, most of the heat energy required for the welded joint comes from the induction coil. The process has many advantages over the butt friction welding method that determine the industrial application of the new technology. The advantages certainly include the lack of butt, an option of welding various materials, easy control of process parameters, short cycle time, and process stability. One of the companies using this technology is Federal Mogul Gorzyce based in Poland, using low force friction welding to produce small steel pistons. This paper analyses the low force friction welding process. The key process parameters, welding stages, and an analysis of the welded joint were presented. This paper discusses the issue of low force friction welding because of the attractiveness of this technique for the industrial application and the scarcity of literature relating to this process.
\end{abstract}

Index: Welding machine, hybrid induktion welder, process analysis, low force friction welding process.

\section{INTRODUCTION}

Friction welding has been known since the last century when the first patent on the use of frictional heat to join materials was issued in England in 1891. Since then, research work has been carried out in many countries around the world resulting in the industrial use of the welding process and the creation of numerous variations of this process. The advantage of the friction welding method is: process cleanliness, possibility of automation, smaller heat-affected zone, high energy efficiency, low cost of joining elements, high material savings and very production time [1-3]. Friction welding in particular allows easy production of joints with high reliability and efficiency; it is widely used in industry [4].

One of the variations of the solid state friction welding process is the low force friction welding process developed by Manufacturing Technology INC (MTI) and EWI also called hybrid technology used for linear and rotary welding. In this process, the energy required for the process is supplied externally. The process of joining two materials in the solid state involves bringing the atoms of the materials to be joined closer together at a distance in the range of the crystallographic lattice characteristics, allowing the interaction between atoms located on the surfaces of the components to be joined to occur.

Manuscript received: 25 December 2021

Manuscript received in revised form: 20 January 2022

Manuscript accepted: 06 February 2022

Manuscript Available online: 15 February 2022
The process of bringing the atomic forces between atoms, ions and molecules closer together at a distance can be facilitated by growing temperature or applying a downforce to the joined components. Therefore, the process of joining materials in the solid state is considered in the parameter system of contact force vs. temperature. [5] The relationship between temperature and contact force to obtain a welded joint is shown in Fig. 1. Friction welding is carried out in zone II, whereas in zone I very high forces are needed for the process to occur, while in zone III we are dealing with liquid metal.

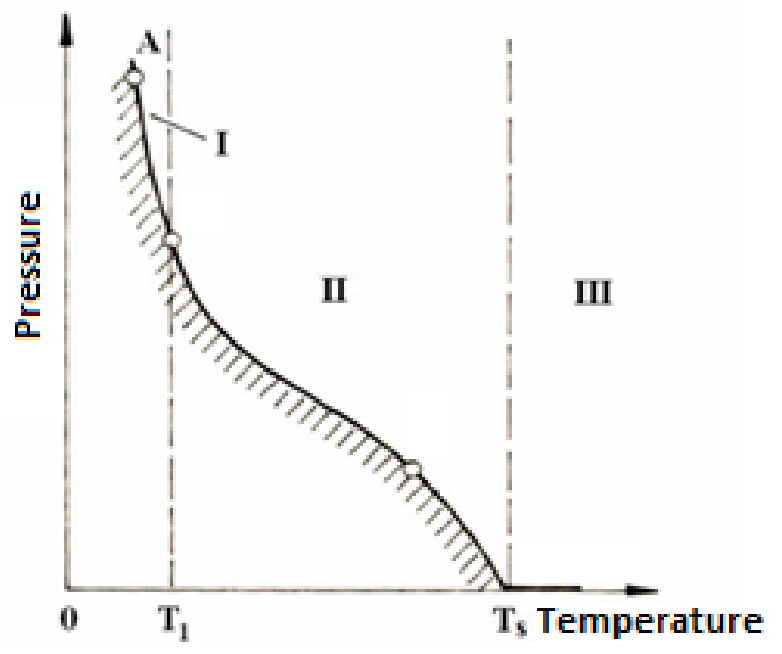

Fig. 1. A graph showing the relationship between temperature and downforce to achieve a bonded joint. [6]

\section{PROCESS ANALYSIS}

The friction welding is a solid state welding process; it is one of the most suitable methods for joining different materials [7]. Rotary Friction Welding is the most commonly used method in friction welding. it is used in two ways: inertia friction welding and continuous drive friction welding [8]. However, the Rotary Friction Welding process has a limitation of use, since it cannot be used for welding parts with a non-circular cross section [9]. In continuous drive method, a rotating sample is pressed against a stationary sample. The friction at the interface generates the welding heat. Finally, the rotation stops and a forging pressure is introduced to achieve the bonding [10]. As it is reported, several welding parameters affect the quality of friction welds, such as friction time, forging time, friction pressure, forging pressure, and rotational speed $[11,12]$. In general Rotary Friction Welding consists of two phases: a friction phase to generate the necessary heat and a forging phase to consolidate the weld [13]. 
ISSN: 2277-3754

ISO 9001:2008 Certified

\section{International Journal of Engineering and Innovative Technology (IJEIT)}

Volume 11, Issue 7, January 2022

The low force friction welding process uses a combination of two types of energy for the joining process, i.e. inductive heating of the component contact surfaces and frictional force between the components. The materials are preheated by a coil using resistance to heat the components' contacts. The remaining energy required in the welding process comes from frictional forces. The ratio of the energy from the coil and the friction process, depending on the selected process parameters, is 9 to 1 . Preheating of the components to be welded reduces the forces needed to make the weld as opposed to the traditional friction welding process. Once the components have been preheated, they are pressed against each other and bolted together at the angle determined in the process. This technology is used to weld components made of steel, aluminium, stainless steels, copper, titanium, and nickel superalloys. [14]

The low force friction welding process consists of five steps:

- fixing of welded intermediate products,

- positioning of intermediate products and coil,

- induction heating of the welded components,

- friction welding,

- unloading of the welded product

Depending on the need, the parts can be loaded manually or automatically by a robot. Clamping, on the other hand, is done by special collets clamped by hydraulic cylinders in order to transmit pressure and torque. Positioning is to determine the actual position of the welded blanks and the induction coil. The mounted blanks are pre-pressed to check their actual heights. After pressing the parts together, the upper sleeve is clamped and then fixed to eliminate the unevenness of the surfaces of the welded blanks. After this operation, the welded blanks move back to the welding position, allowing the induction coil to enter between the welded parts. The induction coil is designed for the specific shape of the components to be welded in order to ensure the most uniform heating process possible. Before starting the induction coil, the coil is purged with nitrogen to ensure that the process takes place in an oxygen-free atmosphere. The coil has the ability to move in such a way as to ensure its centering between the components to be welded. Once the position of the coil is fixed, the generator is switched on with a frequency, power and heating time defined in the process. The intermediate products are heated by the alternating magnetic field created by the high frequency AC current flowing through the coil.

To ensure process stability, the actual temperature of the components is measured and recorded by two piezometers installed. After the set heating time, the induction coil is driven off to start the actual friction welding process with low downforce. The process is started by driving the upper part to the lower part with the pressure force specified in the process. After the two intermediate parts come into contact, a rotational movement of the lower part with a specified speed and angle takes place. After the rotational movement, the welded blanks are pressed against each other for a specified time and cooled. After the set cooling time, the nitrogen supply is stopped and the welded blanks return to the unloading position. Fig. 2 shows the welded blanks during heating, joining and cooling.

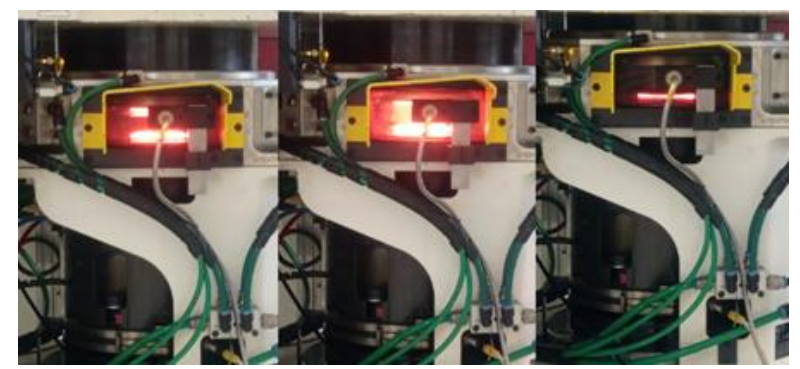

Fig. 2. View of intermediate products welded in successive process phases.

An example of a low force friction welding station is shown in Fig. 3. The machine consists of a welded bed on which are mounted two clamping devices for the upper and lower intermediate product, two hydraulic cylinders, a rotary motion drive and an induction coil. Clamping is carried out by hydraulic cylinders that produce a clamping force. The stroke of the upper part holder is controlled by the attached two hydraulic cylinders responsible for the downforce in the welding process.

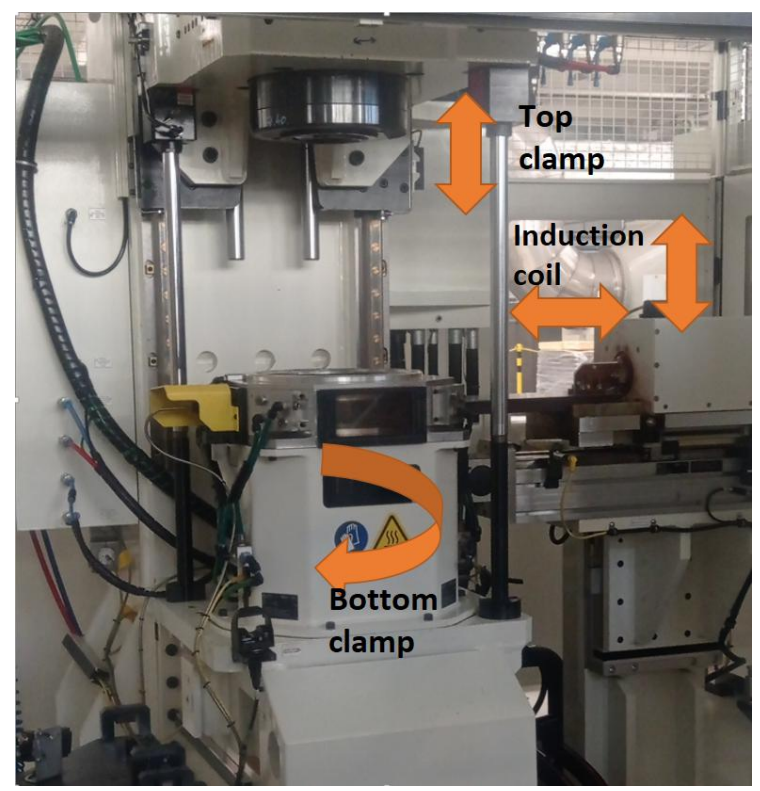

Fig. 3: MTI's 150 HIW low force friction welding machine.

The coil fixing elements are cooled by a coolant supplied to them to prevent the elements from overheating during continuous operation. The heating and welding process takes place in a protective atmosphere of Nitrogen. Nitrogen is supplied to the welding chamber. The argon flow is controlled and monitored in real time to ensure an oxygen-free process. The coil is mounted on a special linear motor for precise positioning between the two intermediate components to be welded. 
ISSN: 2277-3754

ISO 9001:2008 Certified

International Journal of Engineering and Innovative Technology (IJEIT)

Volume 11, Issue 7, January 2022

In order to control the process, the machine manufacturer provides controls for a large number of parameters, the with the key ones such as : welding pressure of intermediate products [bar], angle of rotation of the lower part in relation to the upper part during the welding phase $\left[^{\circ}\right]$, speed of rotation of the lower part in relation to the upper part during the welding phase $\left[^{\circ}\right]$, preheating position [mm], coil power [\%], heating time of elements [ms], stroke limitation [mm], welding and cooling time [ms]. Fig. 4 shows a graph of the change in the values of selected parameters over time. The vertical lines indicate the element positioning stage, the coil heating and positioning stage, and the actual welding process. For comparison, Fig. 5 shows the parameters of rotary friction welding in the time axis.

Low force friction welding has numerous advantages as opposed to the conventional welding process. One of them is that there is little or no extrusion of flash from the friction welding process, Fig. 6 shows the flash from low force friction welding and Fig. 7 shows the flash under the rotation friction welding process. The differences in size and shape of the flashes can be seen.

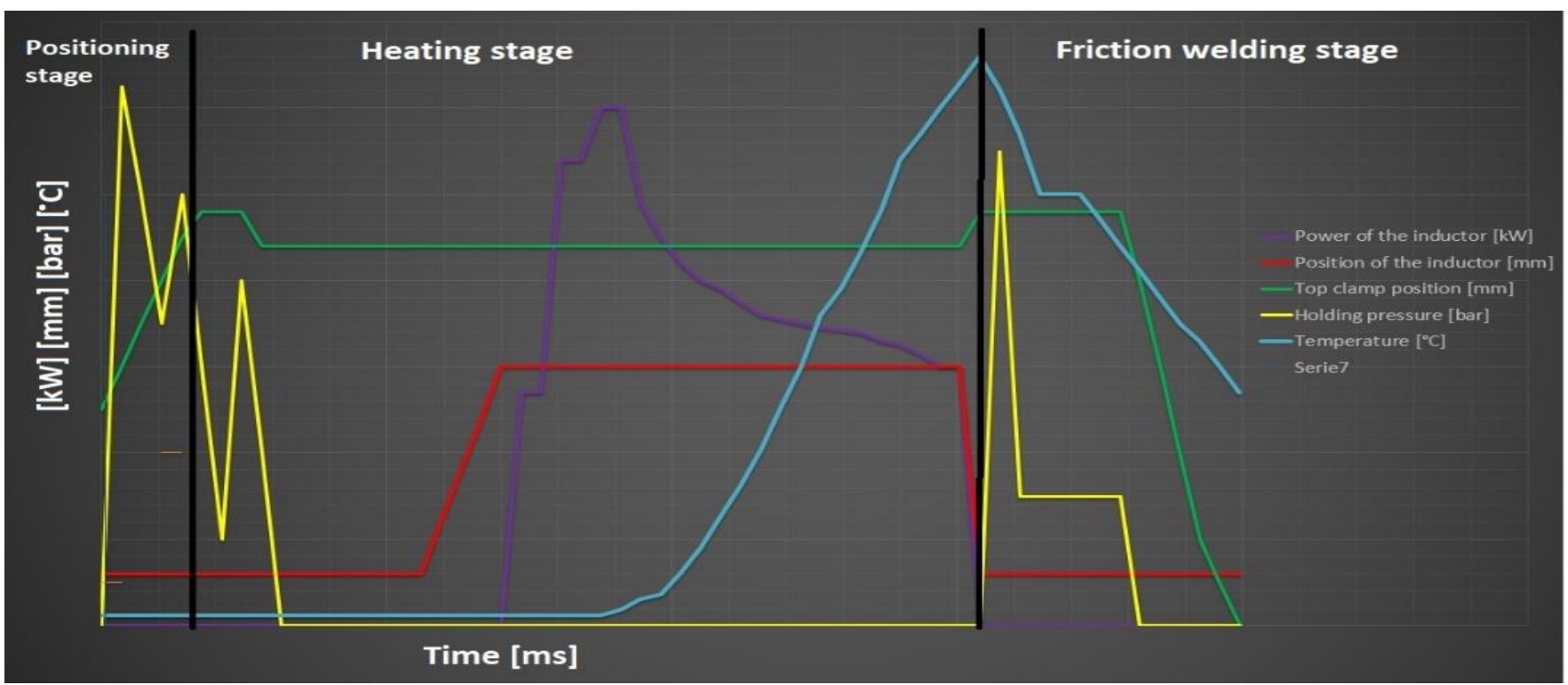

Fig. 4. Diagram of selected welding machine parameters during operation.

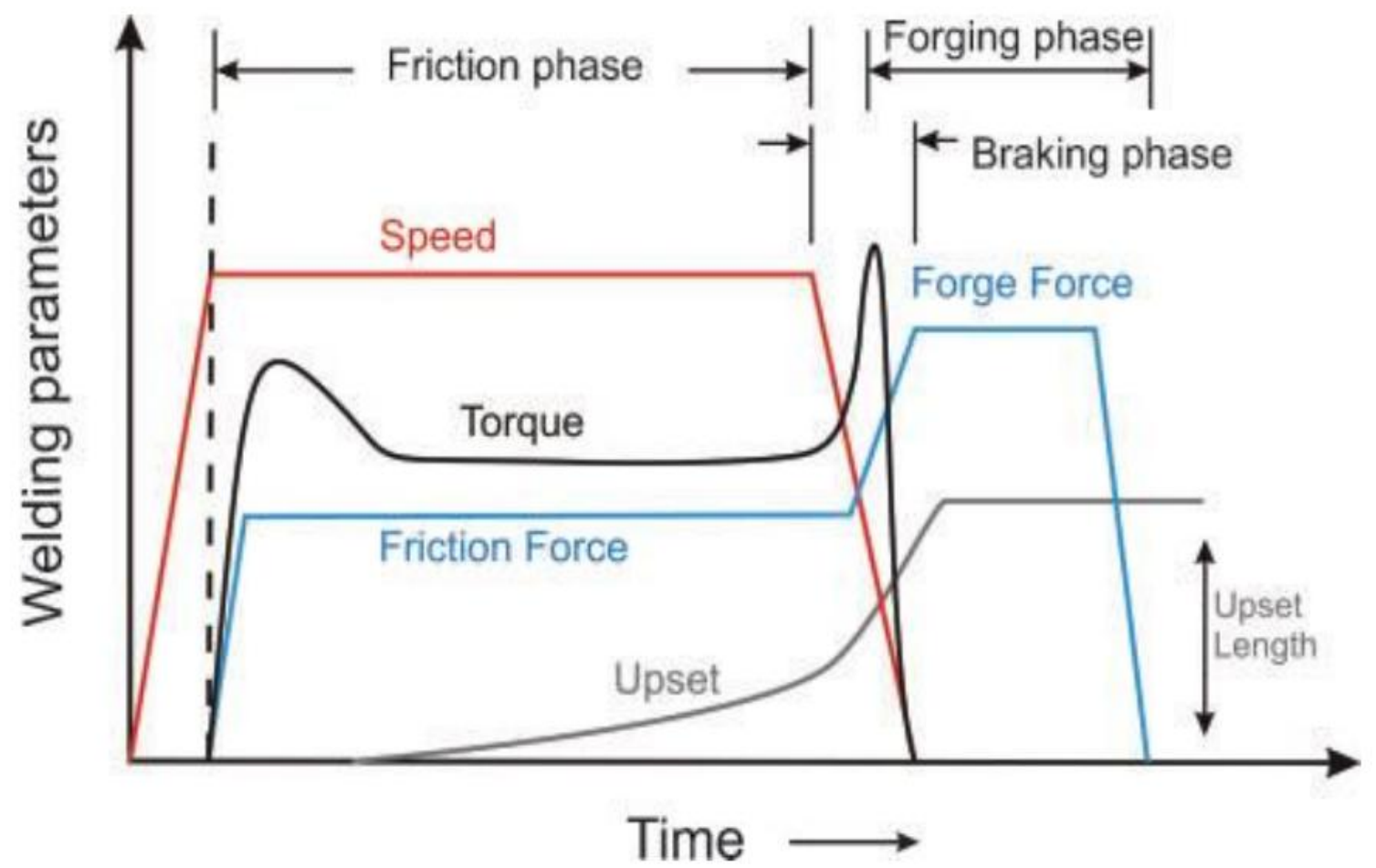

Fig.5. Rotary Friction welding parameters. [15] 
ISSN: 2277-3754

ISO 9001:2008 Certified

International Journal of Engineering and Innovative Technology (IJEIT)

Volume 11, Issue 7, January 2022

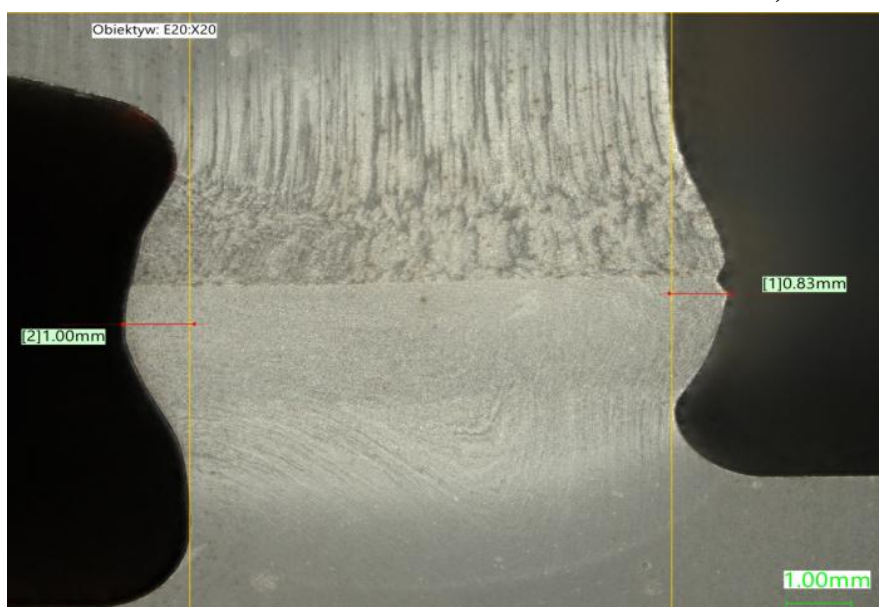

Fig. 6. The shape of the flash under the friction welding process and low force friction welding process.

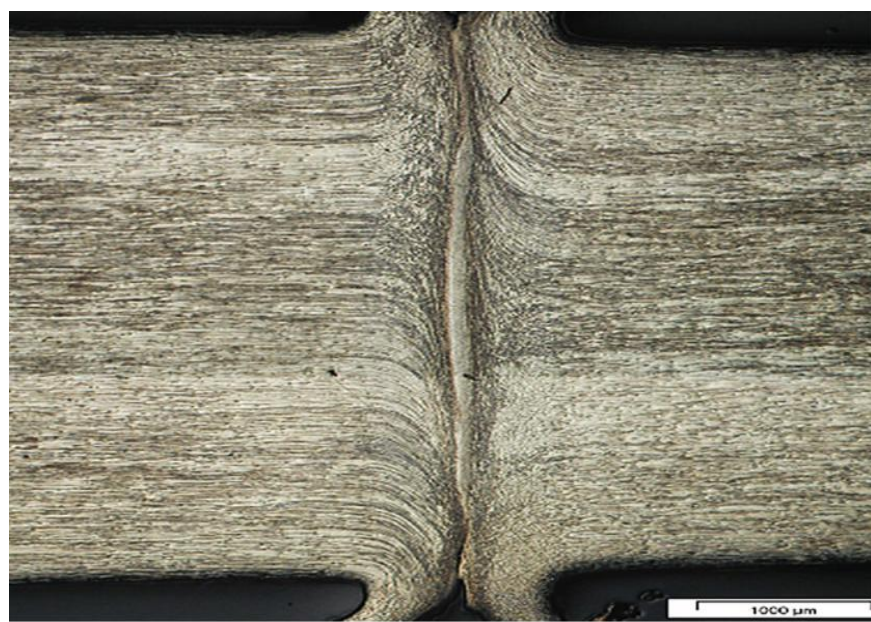

Fig. 7. The shape of the flash under the rotation friction welding process. [16]

Fig. 8 shows the differences in the size of the welding machines. On the left we can see a friction butt welding machine and on the right a low force friction welding machine from MTI. The reduction in welding machine size is particularly important for companies that have limited production space and have to reckon with the size of their production machines when building manufacturing lines under green field projects.

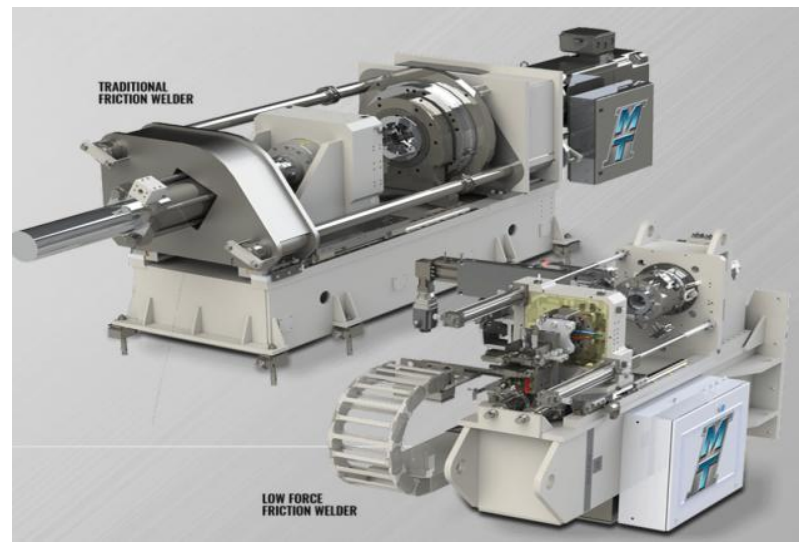

Fig. 8. Size comparison of friction butt welding machine and low force friction welding machine of MTI enterprises. [17]

\section{ANALYSIS OF A WELDED JOINT}

The analysed welded joint was made of 25HM steel using a 150HIW Hybrid Induction Welder from MTI Welding. A forging with a rolled bar was welded. The components were inductively heated to a temperature of approximately $1370^{\circ}$ in an argon envelope. After reaching the set temperature the upper component was pressed against the lower component and the lower component was rotated by $30^{\circ}$ against the upper component. The final result is a small steel piston for internal combustion engines made by Federal Mogul Gorzyce.

$25 \mathrm{HM}$ grade steel is classified as structural steel for quenching and tempering and also as boiler steel for elevated temperatures. Due to the chemical composition shown in tables. 1 it is suitable for tempering and has good mechanical properties including tensile strength. It is commonly used in aerospace, automotive and machine-building industries.

Intermediate products made using low force friction welding are shown in Fig. 9. In the lower view we can see a steel forging, while in the upper view we can see a machined rolled bar. In our case we are dealing with two rings. The inner one on the piston chamber side and the outer one on the piston shell side. The shape of the extrusion of flash affects the flow of oil in the cooling channel, while the quality of the weld determines the piston strength.

Visual testing allows for an initial assessment of the quality of welded joints. The shape and size of the flash are evaluated. Fig. 10 shows the friction welded joint under analysis. The flash should be smooth and symmetrical with no visible burrs or discontinuities. The analysed process has a very high repeatability, an option of changing parameters affecting the shape of the extrusion of flash and their quality control in real time. Due to the conditions in the internal combustion engine, no cracks, discontinuities or structural defects are allowed. The product could be considered as properly made when both welded rings are properly made at the same time. The detection of a defect in even one ring results in the rejection of the product from the further manufacturing process, which is why the reliability of the low force friction welding process is so crucial.

One of the types of non-destructive testing performed during the analysis process is ultrasonic testing. It uses the pulse-echo method, which allows for the detection of missing connections on the welded surfaces and cracks in the weld. In an ideal welded joint the generated ultrasonic wave passes axially through the welded element reflecting from the external surface. When the signal encounters a defect it is reflected in whole or in part creating echoes of various distances. The measurement itself is performed by attaching a probe that generates high-frequency mechanical vibrations in a water medium. The head consists of a piezoelectric transducer excited by an ultrasonic flaw detector. Two parameters are distinguished here, that is, the sum of the areas of all discontinuities of the welded joint of the outer and inner ring and the area of the largest discontinuity separately on each ring expressed in square millimetres. 


\section{|ШEIT}

ISSN: 2277-3754

ISO 9001:2008 Certified

International Journal of Engineering and Innovative Technology (IJEIT)

Volume 11, Issue 7, January 2022

Table 1. Chemical composition of $25 \mathrm{HM}$ grade steel

\begin{tabular}{|l|l|}
\hline \multicolumn{2}{|c|}{ Chemical composition \% } \\
\hline $\mathrm{C}:$ & $0,22-29$ \\
\hline $\mathrm{Mn}:$ & $0,4-0,7$ \\
\hline $\mathrm{Si}:$ & $0,17-0,37$ \\
\hline $\mathrm{P}:$ & $<0,035$ \\
\hline $\mathrm{S}:$ & $<0,35$ \\
\hline $\mathrm{Cr}:$ & $0,8-0,11$ \\
\hline $\mathrm{Mo}:$ & $0,15-0,25$ \\
\hline $\mathrm{Ni}:$ & $<0,3$ \\
\hline
\end{tabular}

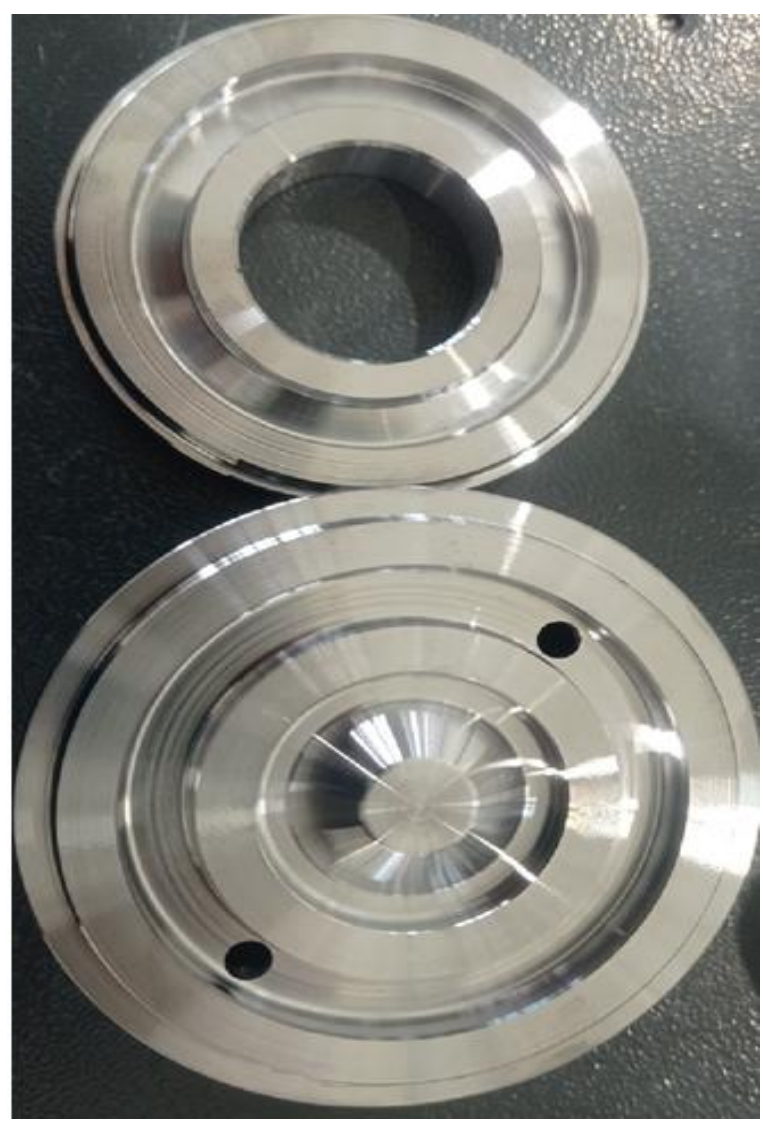

Fig. 9. Low force frictionally welded intermediate products.

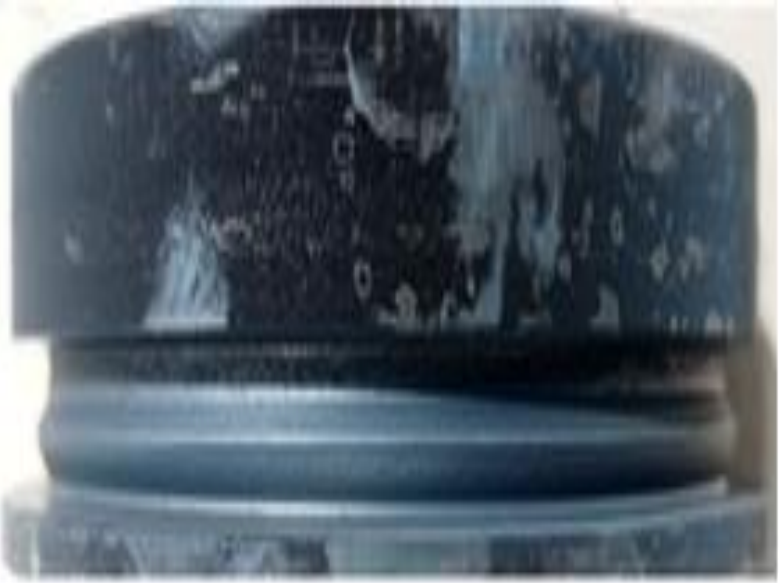

Fig. 10. The low force friction welded joint under study.

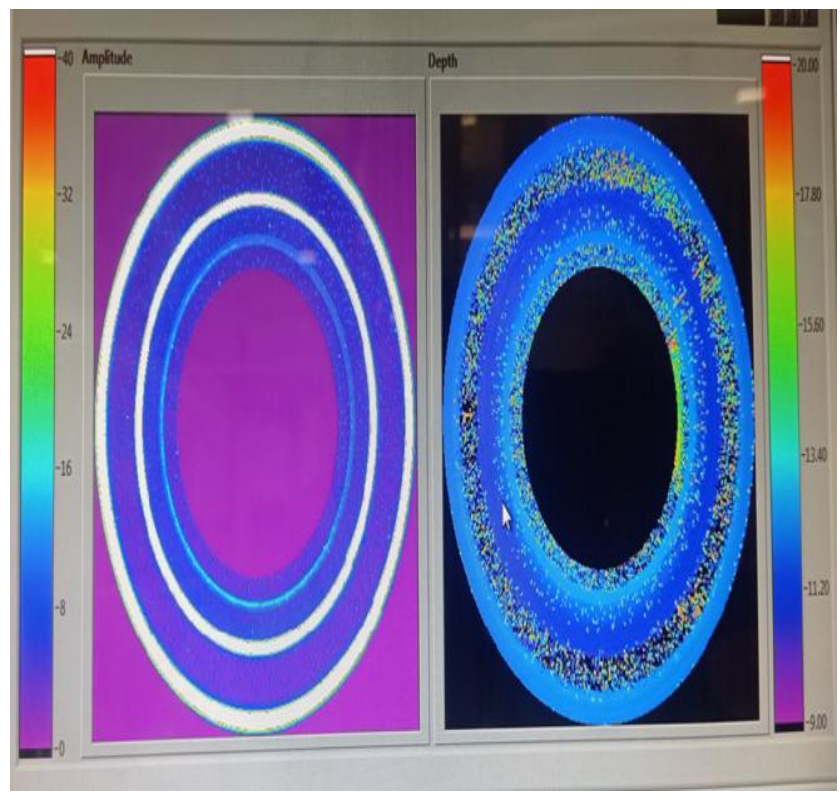

Fig. 11. Analysed intermediate products made using low force friction welding

A weld made using the friction welding technique can be divided into several distinct zones shown in Fig. 12. The central zone of the weld is designated as WCZ, the thermo mechanical impact zone - TMAZ, and the heat-affected zone HAZ. The WCZ and TMAZ zones are thermo mechanical impact zones, but are often considered separately due to their very different microstructures. Depending on the process parameters, the strength properties of the welded joint are either similar or better than the parent material. [18]

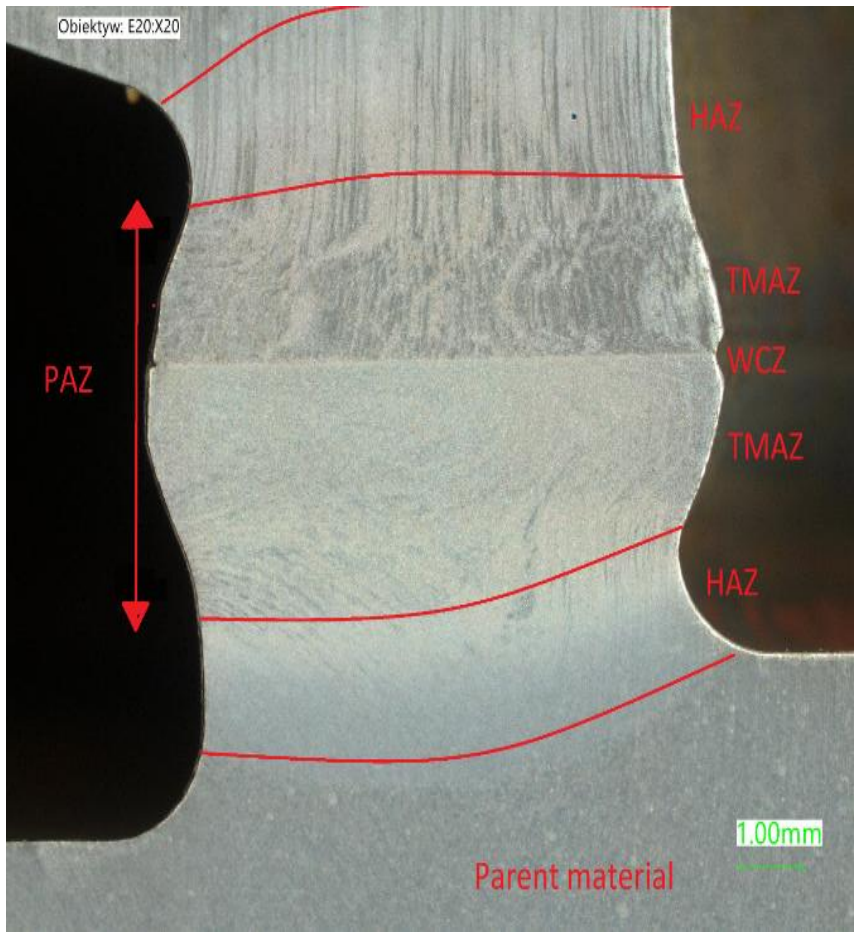

Fig. 12. Determined weld zones performed by low force friction welding. 


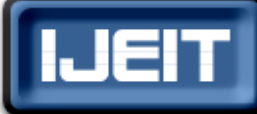

ISSN: 2277-3754

ISO 9001:2008 Certified

International Journal of Engineering and Innovative Technology (IJEIT)

Volume 11, Issue 7, January 2022

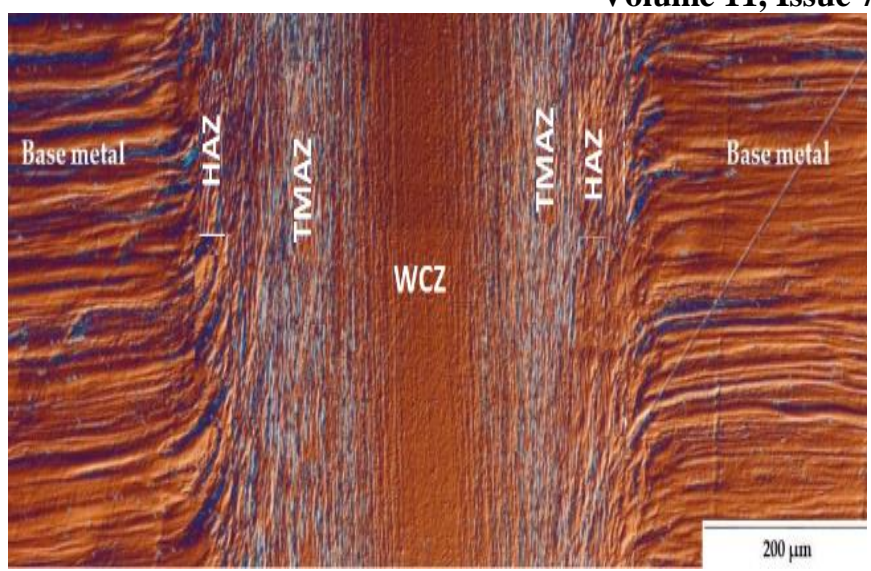

Fig. 13. Microstructure of the rotation friction welding joint from 316L. [18]

The size of the individual zones depends on the material to be welded and the process parameters. In order to increase or decrease the heat affected zones, the power of the induction coil and the preheating time of the parts to be welded can be adjusted. Fig. 12 shows a piece of a welded steel piston where the lower part is made as a forging and the upper part as a bar. For comparison, Fig. 13 shows the microstructure of a Frictional Rotary welding.

Example microstructures of a low force welded joint for 25HM grade steel for $35 \mathrm{~mm}$ by $17 \mathrm{~mm}$ bars are shown for different zones. The heat affected zone of the HAZ is shown in Fig. 14. It can be seen that the parent material consists of hardened martensite which, approaching the central weld zone, changes into newly nucleated austenite grains resulting from the martensite decomposition. The transition size is approximately $300 \mu \mathrm{m} .[5]$

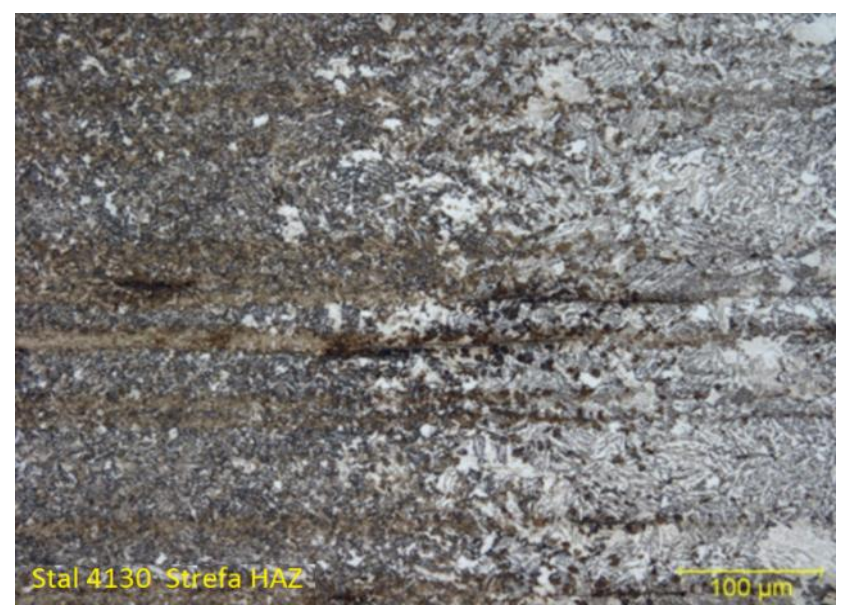

Fig.14. Microstructure of HAZ zone for low force friction welding for 25HM grade steel. [5]

The microstructure in the thermomechanical influence zone of TMAZ is shown in Fig. 15. It is a martensitic structure with visible segregation of the material on the native material side. The central zone of the WCZ weld in Fig. 16 shows a martensitic structure. In this zone the residual segregation is not as linear as in the TMAZ zone, which is the result of the complex process of deformation (translational activity) of this zone during the welding process.

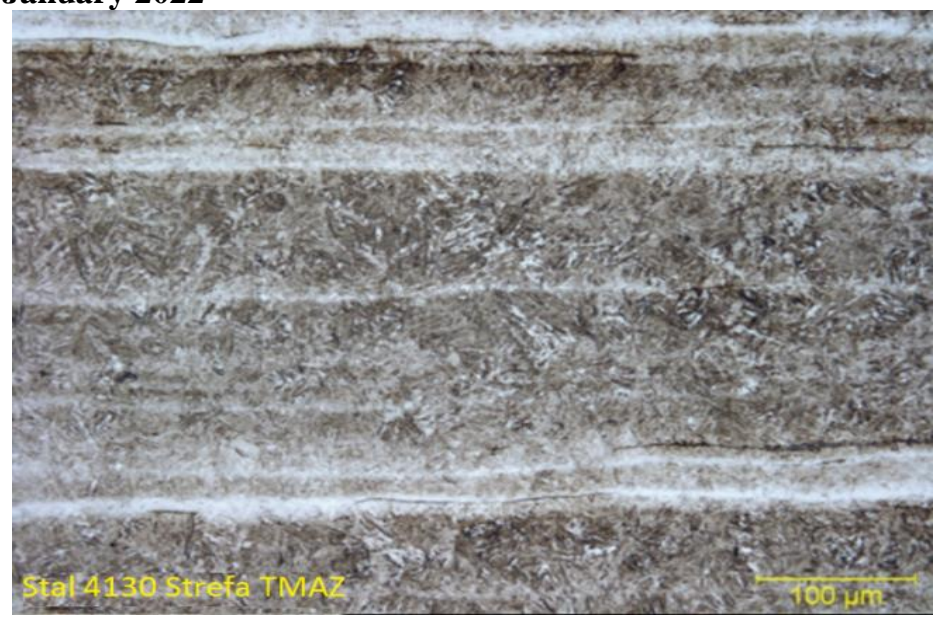

Fig. 15. Microstructure of TMAZ zone for friction welded 25HM grade steel [5]

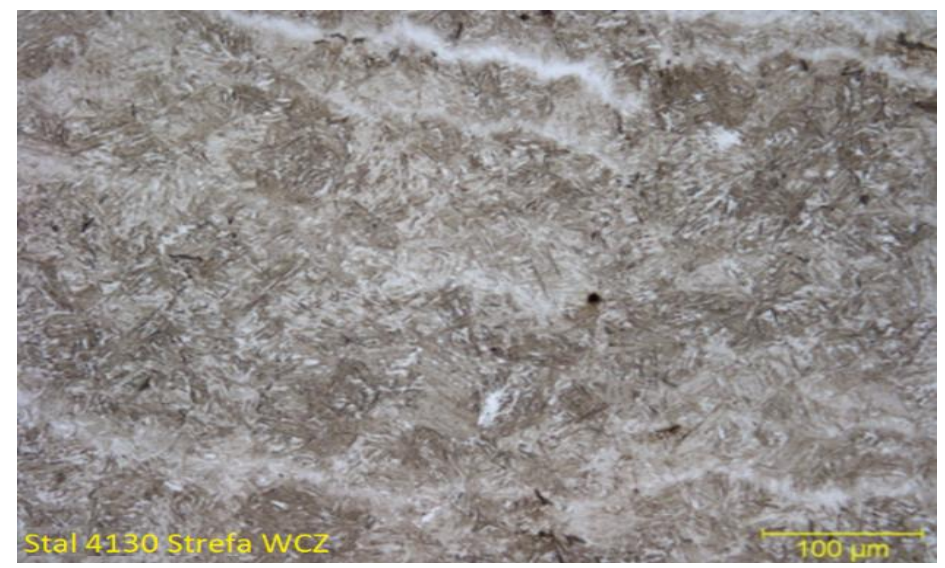

Fig. 16. Microstructure of WCZ zone for friction welded 25HM grade steel. [5]

The hardness measurement was performed with Vickers indenter by taking the measurement at two points, i.e. at the outer and inner ring weld. The distance between the measuring points is $0.5 \mathrm{~mm}$ in a zigzag pattern. The positions of the measuring points are determined in such a way that a minimum of 5 measuring points are made in each weld zone. The hardness measurement serves to qualitatively assess the welded joint. Fig. 14 shows a view of the tested welded joint with hardness measurement traces. The figure shows the size of the heat affected zone and the size of the flash extraction. Both qualitative parameters are easily controlled by changing the process parameters according to the user's needs. The size of the HAZ zone can be changed by varying the induction coil power and heating time, while the size of the flash can be changed by varying the material temperature, downforce and rotation angle.

Figure 17 shows the hardness curve of a weld made by friction welding with low clamping force made of semi-finished 25HM steel. It should be noted here that the hardness measurement was performed on the weld without heat treatment. Hence, such high hardness values in all weld zones. The values of the measured hardness values are represented by the blue points and their combination forms the weld hardness curve. The vertical lines represent the weld 
ISSN: 2277-3754

\section{ISO 9001:2008 Certified \\ International Journal of Engineering and Innovative Technology (IJEIT)}

Volume 11, Issue 7, January 2022

zones, while the red curve is a polynomial trend curve. The hardness increases rapidly from about $300 \mathrm{HV}$ in the parent material to about $500 \mathrm{HV}$ in the HAZ zone. The HAZ zone in the analysed case is about $2 \mathrm{~mm}$ wide on either side. The TMAZ zone is about $6 \mathrm{~mm}$ wide, and the hardness in this zone reaches a maximum of $600 \mathrm{HV}$ and a minimum of approximately $510 \mathrm{HV}$.

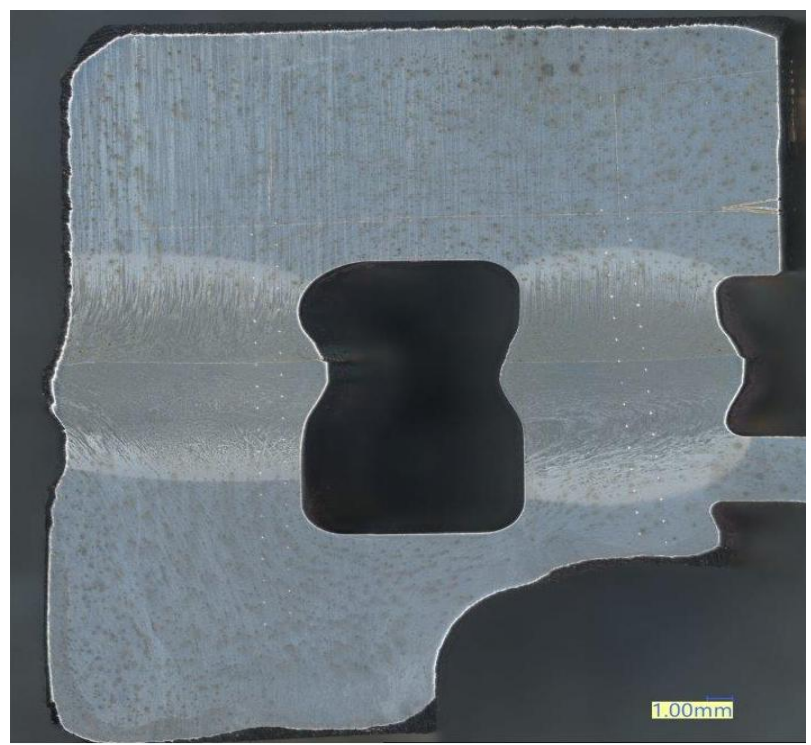

Fig. 17: View of the tested welded joint, with traces left by the hardness measurement.

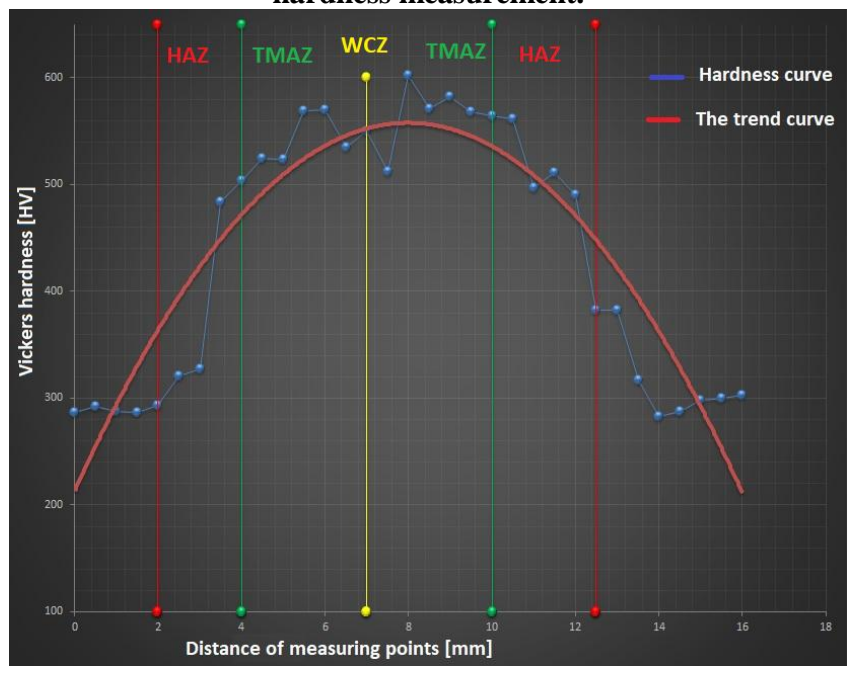

Fig. 18. Hardness curve of the outer ring weld performed using the 150HIW Hybrid Induction welding machine

Fig. 19 shows the hardness curve of the inner ring weld made on the 150HIW Hybrid Induction welder. In this weld the width of the heat affected zone on the material is larger and is almost $12 \mathrm{~mm}$, this may be related to the different widths of the welded rings. As in the earlier case, the TMAZ zone has a maximum hardness of about $600 \mathrm{HV}$ and a minimum hardness of about $510 \mathrm{HV}$. The TMAZ zone has a width of about $6 \mathrm{~mm}$. In both cases the central zone is located symmetrically in relation to the individual zones. On the grounds of the analysed example, it can be seen that the analysed technology provides the possibility of friction welding of details with several connected surfaces with different surface areas forming internal channels with very good flow parameters without the characteristic extrusion of flash as in the butt friction welding process.

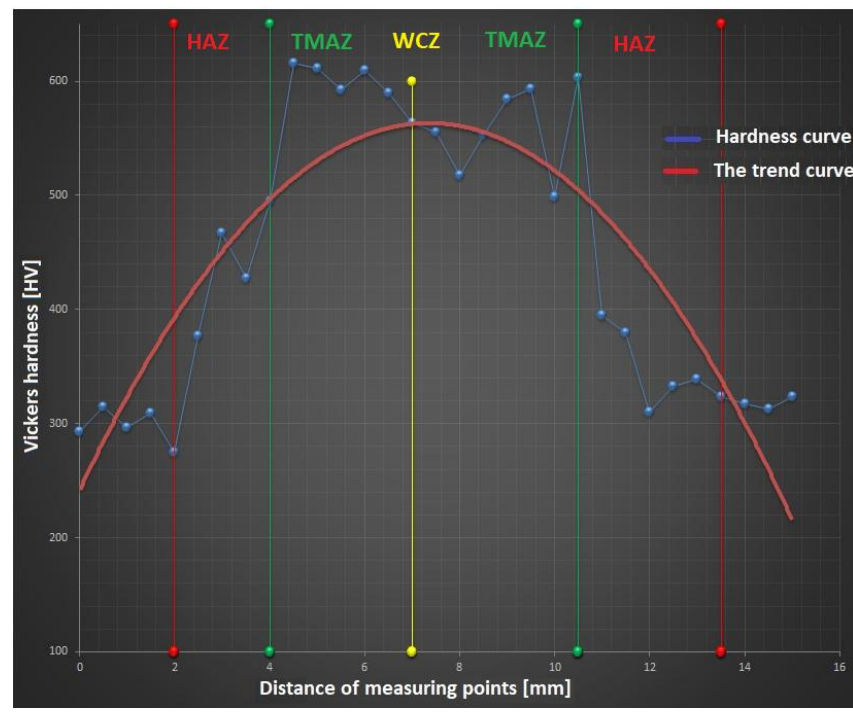

Fig. 19. Hardness curve of the inner ring weld performed using the 150HIW Hybrid Induction welding machine

To compare the two types of welding, Fig. 20 shows the hardness curve of a weld made by rotary friction welding. In this variant, the hardness curves have the shape of the letter $\mathrm{V}$.

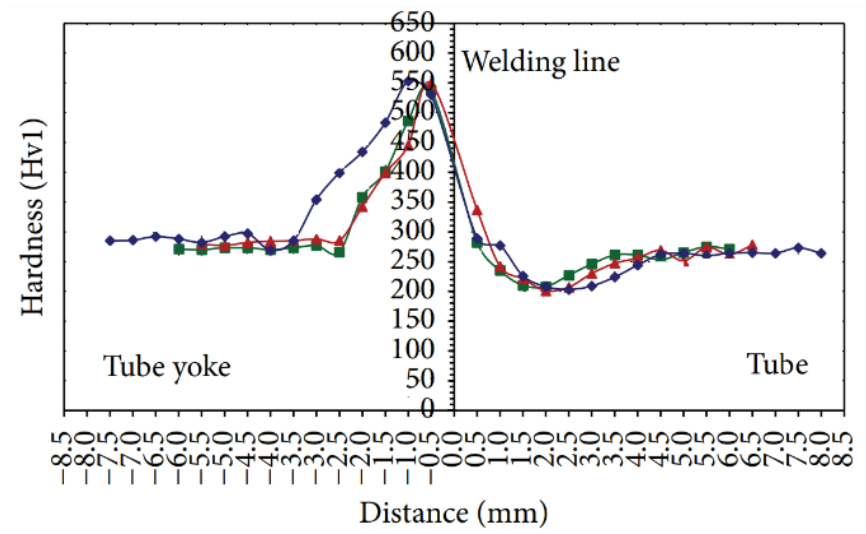

Fig. 20 Hardness curve of the rotation friction welding. [17]

\section{CONCLUSION}

The low force friction welding technology developed by MTI and EWI greatly expands the opportunities for joining materials by friction welding through incorporation of products previously inaccessible due to significant process forces and large extrusion of flash. By negating the forces required for the welding process, the process can be applied to thin-walled, flabby components that could not be welded with older welding methods due to high downforces. In addition, heating the material by means of an induction coil enables the control of the size of the heat-affected zone and thus enables the user to manage the properties of the material in the weld zone. Reducing the time of heating the connected components by friction also reduces the cycle time, which can be seen very 
ISO 9001:2008 Certified

International Journal of Engineering and Innovative Technology (IJEIT)

Volume 11, Issue 7, January 2022

well in the case of welded elements with large cross-sections. For the process owner, the reduced cycle time means a tangible benefit in the form of more welded parts per time unit. The very high precision of the orientation, an option of adjusting the axes to fit the components to be welded, the real-time feedback loops of the process parameters guarantee the repeatability of the welded parts. Lower process forces also mean a smaller machine. An example is the patented solution of the Federal Mogul Corporation called the HIW process, which involves making a steel piston from two halves welded with the use of the above-described technology, thanks to which a steel piston without extrusion of flash in the cooling channel area, without micro-cracks and residual stresses is created, with visibly superior strength performance. At the same time, the lack of extrusion of flash in the cooling channel ensures better cooling, extending the engine operational life. Finally, there are possible improvements to the friction raking process. Improvements on the one hand should concern the position and on the other hand the process. The improvement of the friction welding station consists in optimizing the strength of the fastening and force transmitting elements by eliminating notches and using new materials. One should also mention the reduction of tooling costs by using the production scale effect and the maximum unification of tooling. On the other hand, there should be process optimization through the use of artificial intelligence. The use of neural networks and Fuzzy logic would make it possible to shorten the time of launching new products, eliminate defective products of the welding process and improve the quality of welds. Using learning algorithms, we are able to generate optimized process parameters on the basis of data from the measurement of weld discontinuities, minimizing the formation of defective products. On the other hand, using Fuzzy logic and neutron networks, it is possible to shorten the time of changeover to a new product by setting the process parameters by an algorithm that analyzes the most optimal process parameters of other products.

\section{REFERENCES}

[1] K. S. Sreenivasan, S. S. Kumar, J. Katiravan, "Genetic algorithm based optimization of friction welding process parameters on AA7075-SiC composite", Engineering Science and Technology, International Journal, 22, 2019, pp: $1136-1148$

[2] N. Titouche, T. Boukharoubab, S. Amzert, A. J. Hassan, R. Lechelah, S. Ramtani, "Direct drive friction welding effect on mechanical and electrochemical characteristics of titanium stabilized austenitic stainless steel (ALSI 32) research reactor thick tube", Journal of Manufacturing Processes, 41, 2019, pp:73-83.

[3] A. Kurt, I. Uygur, U. Paylasan, "Effect of Fraction Welding Parameters on Mechanical and Micrstructural Properties of Dissimilar AlSi-ASTM B22 Joints", Welding Journal, 90, 2011,pp:102-106.

[4] E. Bouarroudj, S. Chikh, S. Abdi, D. Miroud, "Thermal analysis during a rotational friction welding", Applied Thermal Engineering, 110, 2017, pp:543-553.
[5] Ambroziak A., "Friction welding of materials with different properties", publishing House of the Wroclaw University of Technology, Wroclaw 2011, pp: 3-14.

[6] WB Lee, YM Yeo, DU Kim, and SB Jung, "Effect of friction welding parameters on mechanical and metallurgical properties of a 5052-A 36 aluminum alloy joint", Mother. Science. Technol., Tom. 19, 2003, pp. 773-778.

[7] M. Sahin, "Joining Aluminum and Copper Materials by Friction Welding". Inside J. Przys. Producer Technol., Tom. 49, 2010, pp. 527-534.

[8] AB Dawood, SI Butt, G. Hussain, MA Siddiqui, A. Maqsood, and F. Zhang, "Thermal Friction Rotational Welding Model for Like and Dissimilar Metals." Metals, Tom. 7, 2017, pp. 1-14.

[9] B. S. Yilbas, A. Z. Sahin, A. Coban, and B. J. Abdul-Aleem, "Investigation into the properties of friction welded aluminum bars.” J. Mater. Process. Technol., vol. 54, 1995, pp. 76-81.

[10] S. T. Selvamani, K. Palanikumar, K. Umanath, and D. Jayaperumal, "Analysis of friction welding parameters on the mechanical metallurgical and chemical properties of AISI 1035 steel joints", Mater. Des. vol. 65, 2015, pp. 652-666.

[11] N. Ozdemir, "Investigation of the mechanical properties of friction- welded joints between AISI 304L and AISI 4340 steel as a function rotational speed", Mater. Lett., vol. 59, 2005, pp. 2504-2509.

[12] F.Khalfallahfa, Z.Boumerzoug, S. Rajakumar, and E. Raouache, "Optimization by RSM on rotary friction welding of AA1 100 aluminum alloy and mild steel", International Review of Applied Sciences and Engineering, 2020, pp: 34-42.

[13] Jerry E. Gould, EWI Dan Adams, "Low Force Friction Welds in 4130 Steel, A Preliminary Microstructural Characterization", Manufacturing Technology, Inc. 2020, pp: $1-8$.

[14] Aswin Pranav Ramesh, Madheswaran Subramanian, Prakash Eswaran, "Review on friction welding of similar/ dissimilar metals", Journal of Physics: Conference Series, 2019, pp: 1-15.

[15] Beata Skowronska, Piotr Siwek, "Friction welding of ultra-fine-grained 316L steel", Arch. Metall. Mater. 64, 2019, pp: 1051-1058.

[16] Anthony R. McAndrew , Paul A. Cole grove , Clement Buhr Bertrand C.D. Flipo, "A literature review of Ti-6Al-4V linear friction welding", Progress in Materials Science,2018,pp:225-257.

[17] Beata Skowronska ,Tomasz Chmielewski, Mariusz Kulczyk Jacek Skiba and Sylwia Przybysz, "Microstructural Investigation of a Friction-Welded 316L Stainless Steel with Ultrafine-Grained Structure Obtained by Hydrostatic Extrusion”, Materials, 2021,PP:1-19.

[18] Efe IGjk, Cicek Ozes, "Determination of the Mechanical Properties of Friction Welded Tube Yoke and Tube Joint", Hindawi Publishing Corporation Advances in Materials Science and Engineering, Volume 2016, pp: 1-9.

\section{AUTHOR BIOGRAPHY}

Paweł Zurawski, M.Sc., engineer, graduate of 3 universities. On a daily basis, he is a constructor of machines and devices, in his free time passionate in the field of production automation and artificial intelligence. Author of 
ISSN: 2277-3754

ISO 9001:2008 Certified

International Journal of Engineering and Innovative Technology (IJEIT)

Volume 11, Issue 7, January 2022

many designs in the automotive industry. Implementation path of innovative

approach to rotational alternative frictional action. Known as low pressure

friction welding 